\title{
Congenital Stridor Due to Bilateral Vocal Cord Palsy
}

\author{
M. Kaushal, A. Upadhyay, R. Aggarwal and A.K. Deorari \\ Division of Neonatology, Department of Pediatrics, All India Institute of Medical Sciences, Ansari Nagar, \\ New Delhi, India.
}

\begin{abstract}
Congenital stridor is one of the rare presentations of respiratory distress at birth. The commonest cause of congenital stridor is laryngomalacia, which accounts for $60 \%$ of the causes. The other common causes are congenital subglottic stenosis and vocal cord palsy (VCP). VCP is usually unilateral and most often linked with birth trauma, and is temporary. Bilateral palsy can be associated with other congenital anomalies. The current report describes a case of congenital bilateral VCP, not related to birth trauma and severe enough to require tracheostomy. [Indian J Pediatr 2005; 72 (5) : 443-444]

E-mail : drrajivaggarwal@hotmail.com
\end{abstract}

Key words : Stridor; Vocal cord palsy; Congenital

\section{CASE REPORT}

A female baby was delivered vaginally to a primigravida at 37 weeks of gestation after an uncomplicated antenatal period. The baby developed stridor soon after birth which was present both during inspiration and expiration, high pitched and loud. Within four hours the baby developed hypoxemia $\left(\mathrm{PaO}_{2}\right.$ of $\left.40 \mathrm{mmHg}\right)$ and hypercarbia $\left(\mathrm{PaCO}_{2}\right.$ of $70 \mathrm{mmHg}$ ) on $100 \%$ oxygen. For this the baby was intubated and put on ventilation. The baby was weaned off ventilator within 24 hours. However, over next 24 hours she again developed $\mathrm{CO}_{2}$ retention. She had good respiratory efforts. An endotracheal (ET) tube was inserted and left in situ. To exclude a transient palsy due to neuroprexia, an extubation trial was given on $16^{\text {th }}$ day of life. However, this attempt failed and tracheostomy was done on $18^{\text {th }}$ day of life. The baby also had hypoplasia of left lower limb below the knee. The measurements of right and left lower limbs revealed a difference of $2 \mathrm{~cm}$ in circumference and length. The baby developed myoclonic seizures on day eight, which responded to Phenobarbitone and clonezepam. Indirect laryngoscopy revealed minimal movements of both vocal cords suggestive of bilateral vocal cord palsy (VCP). To exclude surgical causes; investigations done included $X$ ray neck, barium swallow, ECHO and MRI neck and head; all of which were essentially normal. Direct fluoroscopic laryngoscopy confirmed bilateral VCP. There was no instrumentation done during delivery and no other features of birth trauma were present. Metabolic work up including blood glucose, serum calcium, magnesium, blood gas, lactate and ammonia were essentially normal. Hence a diagnosis of idiopathic VCP was made. An EEG

Correspondence and Reprint requests : Dr. Rajiv Aggarwal, Assistant Professor, Department of Pediatrics, All India Institute of Medical Sciences, Ansari Nagar, New Delhi 110029. done on Day 24 was grossly abnormal. Literature search did not reveal any syndromic relation between VCP, hypoplasia of lower limbs and seizures.

During follow-up the child was evaluated for neuromuscular disorders e.g. fasioscapulohumeral myopathy, spinal muscular dystrophy, and congenital myasthenia gravis. At one year of age, a trial of closing the tracheostomy tube for a few minutes was given but the child still needs the tracheostomy tube. There is no recurrence of seizures in the past 6 months and anticonvulsants have been stopped. Both mental and motor DQ's are mildly abnormal and have been assessed to be 70 .

\section{DISCUSSION}

The most common causes of stridor at birth are laryngomalacia, congenital subglottic stenosis, VCP or vascular compression of trachea. The other causes are tracheomalacia, bronchomalacia and pressure effects of surrounding structures. ${ }^{1}$ In a case series evaluating cause of stridor in babies it was found that Laryngomalacia $(19.4 \%)$ was the commonest congenital cause. ${ }^{2}$ In different case reports from India the other causes of stridor were tracheal duplication, ductus arteriosus aneurysm, subglottic cyst, tracheal and laryngeal agenesis and subglottic stenosis. ${ }^{3-6}$ Babies with stridor need to be referred to an otolarygologist for full evaluation and treatment. The airway should be secured before referral.

\section{Vocal Cord Paralysis (VCP)}

It accounts for $10-15 \%$ of causes of stridor. Bilateral VCP can cause biphasic stridor. Unilateral VCP is more common and is usually associated with birth injury, aberrant vessels and atrial enlargement. Bilateral VCP causes more severe symptoms and aphonia. ${ }^{7,8}$ Often there 


\section{Kaushal et al}

is an associated neurological anomaly like Arnold chiari malformation, intraventricular hemorrhage, meningoencephalocele and hydrocephalus. The other causes of VCP are traumatic forceps delivery, mediastinal surgery, and ligation of patent ductus arteriosus. However, most common cause of VCP is idiopathic.

Investigations which should be done to exclude other causes include a barium swallow, CT scan, MRI and endoscopy. Barium swallow helps to evaluate for aberrant vessels. CT Scan/ MRI head and neck can diagnose masses causing compression, aberrant vessels, mediastinal masses and associated neurological anomalies. Most infants with stridor require flexible direct laryngoscopy for diagnosis. ${ }^{9}$ Flexible fiber optic nasopharyngeal larygoscopy is safe, allows detailed examination of nose, choanae, nasopharynx, oropharaynx and hypopharynx. ${ }^{10}$ It provides information for evaluation of stridor, such as supraglottic soft tissues, vocal fold motion, dynamic compression from masses or cysts and evidence of trauma, tumor or infection. The dynamic view in particular is very helpful in diagnosing laryngomalacia and VCP. It can be done without anesthesia. Rigid endoscopic examination requires anesthesia.

Treatment of unilateral palsy depends on severity of symptoms. Most cases resolve over 6-12 months and hence surgical management is not required. Tracheostomy is often required in $\mathrm{B} / \mathrm{L}$ VCP. Bilateral VCP related to birth injury may improve over two weeks in the presence of neuroprexia and 3-6 months in axontemesis. Therefore, a trial of extubation at 14 days should be given in all cases of B/L VCP even if no obvious history of birth trauma is present. Additionally, in cases failing the extubation, a second trial should be given at 3-6 months. If the second trial also fails, then tracheostomy has to be continued and repair has to be attempted in later life. ${ }^{8}$ Rupa et al found that tracheostomy was performed in $25 \%$ of cases with congenital stridor and the most frequent indication was bilateral abductor paralysis. ${ }^{2}$ Another series showed that bilateral palsy had worst prognosis with only $52 \%$ recovering spontaneously and $7.2 \%$ requiring surgical correction $^{11}$

\section{REFERENCES}

1. Fawehinmi $Y$, Fageeh $N$, Asindi A. Congenital Stridor as seen in a Neonatal Intensive Care Unit in Saudi Arabia. Niger J Pediatr 2002; $29: 11-13$.

2. Rupa V, Raman R. Aetiological profile of paediatric laryngeal stridor in an Indian hospital. Ann Trop Pediatr 1991; 11(2) : 137141.

3. Sen MK, Mehta C, Chakrabarti S, Suri JC. Tracheal duplication as a cause of congenital stridor. Indian J Chest Dis Allied Sci 1999; 41(3) : 159-162.

4. Jha D, Deka RC. Congenital supraglottic cyst: a rare cause of stridor. Indian J Pediatr 2000; 67(4) :311-312.

5. Das BB, Solowiejczyk DE, Kamath V, Sharma J. Congenital ductus arteriosus aneurysm presenting with stridor in a newborn. J Perinatol 2002; 22(2) : 179-180.

6. Sarkar N, Agarwal R, Das AK, Atri S, Aggarwal R, Deorari AK. Congenital airway abnormalities in neonates. Indian I Pediatr 2002; 69(11) : 993-995.

7. Miller RH, Duplechain JK. Hoarseness and vocal cord paralysis. In Bailey BJ, Johnson JT, Kohut RI, Pillsbury HC, Tardy ME, eds. Head and Neck Surgery-Otolaryngology Vol I. Philadelphia: J.B. Lippincott, 1993:620-629.

8. Berke GS. Voice disorders and phonosurgery. In Bailey B], Johnson JT, Kohut RI, Pillsbury HC, Tardy ME eds. Head and Neck Surgery-Otolaryngology Vol I. Philadelphia: J.B. Lippincott, 1993: 644-657.

9. Benjamin BN, Gray SD, Bailey CM. Neonatal vocal cord paralysis. Head Neck 1993; 15(2) : 169-172.

10. Hicks DM. Assessment and documentation of voice disorders. Oper Techniq Otolaryngol Head Neck Surg 1993; 4:196-198.

11. De Gaudemar I, Roudaire M, Francois M, Narcy P. Outcome of laryngeal paralysis in neonates: a long term retrospective study of 113 cases. Int J Pediatr Otorhinolaryngol 1996; 34(1-2) : 101-110. 